U. S. DEPARTMENT OF AGRICULTURE,

BUREAU OF ANIMAL INDUSTRY.-CiRCULAR 154.

DEPOSITORYY

A. D. Melvin, Chief of Bureau.

\title{
THE NEED OF STATE AND MUNICIPAL MEAT INSPECTION TO SUPPLEMENT FEDERAL INSPECTION. ${ }^{a}$
}

\author{
By A. M. Farrington, D. V. M., \\ Assistant Chief, Bureau of Animal Industry.
}

To provide clean, healthful, wholesome meats for rich and poor alike is one of the problems of modern civilization. In the early days, when people lived in rural communities, each householder killed animals of his own raising to supply meats for his own family and for his neighbors. In these days, when people are massed in large towns and cities, it is not possible for each individual to know from personal observation the source of his meat supply.and whether or not it comes from healthy animals.

The purchaser at the retail store or market can determine whether the meat is satisfactory in appearance, price, and cut; but its source and previous treatment are practically a sealed book and positively unknown to the majority of people.

\section{BRIEF OUTLINE OF MEAT INSPECTION IN THE UNITED STATES.}

The first effort to solve the problem of a healthful.meat supply for the people of the United States was begun by the Federal Government in the meat-inspection act of March 3, 1891. ${ }^{b}$ This act was not adequate for the purpose, in that it did not give sufficient authority to supervise all the processes to which meat is subjected. It enabled the Department of Agriculture to certify that the meat of animals at the time of slaughter was free from disease, but it gave no power to follow the meat through the different processes of curing, pickling, smoking, etc., in the packing house, nor did it give authority to supervise the sanitary condition of the rooms or buildings where the meat was handled. This lack of authority has now been remedied by the Federal meat-inspection act of June 30,1906. By this act the extent of the meat inspection conducted by the Government has been greatly increased and enlarged.

During the fiscal year ending June 30, 1906, the meat inspection under the several previous acts had been conducted at 163 establish-

$a$ This article is based on a paper presented at the Twelfth Annual Convention of the Association of State and National Food and Dairy Departments, at Mackinac, Mich., August 4, 1908, and reprinted from the Twenty-fifth Annual Report of the Bureau of Animal Industry (1908).

$b$ The act of August 30,1890, provided for the inspection of meat for export only, and was a commercial rather than a sanitary measure. 
ments in 58 cities and towns. In the fiscal year ending June 30, 1907 , such inspection had been conducted at 708 establishments in 186 cities and towns, while the number of employees required to put in force the provisions of the new act was 2,290 as against 981 under the former act. There was a proportionate increase in the amount of money spent, $\$ 2,159,474$ being the amount expended for the fiscal year 1907 as against $\$ 771,661$ for the previous year. The act of June 30,1906 , makes a permanent annual appropriation of $\$ 3,000,000$ for meat inspection.

With the authority of this law the Secretary of Agriculture may cause to be made by inspectors, appointed by him for that purpose, an examination and inspection of all live cattle, sheep, swine, and goats before they are allowed to enter any slaughtering, packing, meat-canning, rendering, or other similar establishment where meat or meat food products are prepared for interstate or foreign commerce. He is also required to cause to be made by inspectors, appointed by him for that purpose, a post-mortem examination and inspection of the carcasses and parts thereof of all such animals to be prepared for human consumption at any such establishment for transportation or sale as articles of interstate or foreign commerce. The act makes an exception in the case of animals slaughtered by farmers on the farm and by retail butchers and retail dealers supplying their customers.

The law is very explicit and describes in more or less detail how the inspection shall be conducted. It provides for the issuance of regulations which prescribe the manner of making the inspection. Any person engaged in the slaughtering, packing, canning, or rendering of meat food products for interstate or foreign trade must make application for inspection to the Secretary of Agriculture, on blanks furnished for that purpose, stating the number and kind of animals slaughtered or animal products handled, the amount prepared for local consumption, and the amount prepared for interstate or foreign trade, the applicant agreeing to conform to all lawful rules and regulations. On receipt of this application it is sent to the Chief of the Bureau of Animal Industry, who designates an inspector to visit the establishment and report upon its sanitary condition and its facilities for inspection. If alterations are required in order to conform to the regulations the proprietor is notified in writing, and inspection is not commenced until these changes are made or positive assurances given that the plant will be put in a satisfactory condition.

When these preliminary matters are arranged the necessary force of inspectors is detailed for the inspection. A veterinary inspector is assigned to take charge if the establishment is engaged in the slaughter of animals, and he is furnished with a sufficient number of 
assistants to supervise the work according to the regulations. The veterinary inspectors personally conduct the post-mortem inspection of all animals slaughtered. All carcasses which come from healthy animals are marked by a metal or rubber stamp and purple ink with the legend "U. S. Inspected and Passed" and the official number of the establishment.

By selecting meat that bears this stamp consumers are assured that it came from animals found healthy on post-mortem examination. The Federal inspection, however, is limited to establishments that are engaged principally in supplying meat for the interstate or foreign trade. Although some of this meat is no doubt sold for local consumption, a great quantity is put upon sale that does not receive such inspection.

\section{EXTENT OF SLAUGHTER WITHOUT GOVERNMENT INSPECTION.}

It will be interesting at this point to inquire into the number of animals that are killed to be consumed within a State. The slaughter of food animals in the United States may be divided into three classes, as follows:

(1) The wholesale and packing, (2) the slaughter by small butchers, and (3) the farm slaughter. The Bureau of the Census has published figures relating to the first and third classes, but not the second, and those relating to the third are somewhat out of date, as they last appeared in the Eleventh Census (1890).

The general public is intimately concerned with the first two classes, as both of them enter into trade. While the wholesale and packing class is wholly included in the Government inspection, such is not the case with class 2 (small-butcher slaughter). It is, therefore, desirable to ascertain the extent of the latter, so as to determine to what degree the people are dependent upon State and municipal inspection for the wholesomeness of their meat products. Although exact figures can not be given, enough can be shown to indicate that the number of animals annually slaughtered by local butchers is probably very much larger than is generally supposed.

The method adopted to find the required number for the year 1907 is based, first, on the numbers of domestic animals in the country on January 1, 1907, as estimated by the Bureau of Statistics, Department of Agriculture; and, second, on the application to these numbers of certain percentages, representing the total annual kill of each species. The percentages referred to have been previously ascertained and published by the Bureau of Animal Industry in the Twenty-second Annual Report, and may be applied to any normal year of live-stock production.

Having thus obtained an estimate of the total number of the various animals disposed of in 1907, it simply remains to deduct (1) the 
number slaughtered under Federal supervision, (2) the estimated farm slaughter, and (3) the number exported from the country alive. After these deductions there is left a remainder which necessarily represents the small-butcher slaughter, the whole of which is without Federal inspection.

The totals of these various items are given in the statement below:

Estimated number of cattle, sheep, and swine in United States, and number slaughtered, with and without Federal inspection, etc., during $190 \%$.

\begin{tabular}{|c|c|c|c|}
\hline Item. & Cattle. & Sheep. & Swine. \\
\hline $\begin{array}{l}\text { Number in United States January } 1,1907 \text { (as estimated by Bureau } \\
\text { of Statistics, Department of Agriculture) } \ldots \ldots \ldots \ldots \ldots \ldots \ldots \\
\text { Estimated total number disposed of in } 1907 a_{\ldots} \ldots \ldots \ldots \ldots \ldots \ldots\end{array}$ & $\begin{array}{l}72,534,000 \\
14,507,000\end{array}$ & $\begin{array}{l}53,240,000 \\
19,166,400\end{array}$ & $\begin{array}{l}54,794,000 \\
59,725,460\end{array}$ \\
\hline 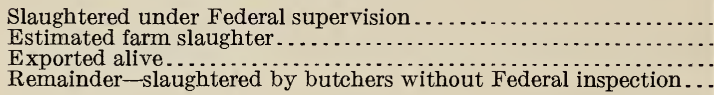 & $\begin{array}{r}7,633,365 \\
1,500,000 \\
401,583 \\
4,972,052\end{array}$ & $\begin{array}{r}10,252,070 \\
1,000,000 \\
121,197 \\
7,793,133\end{array}$ & $\begin{array}{r}32,885,377 \\
16,500,000 \\
23,783 \\
10,316,300\end{array}$ \\
\hline
\end{tabular}

a Percentages applied: Cattle, 20 per cent; sheep, 36 per cent; swine, 109 per cent.

Note.-In addition to the above, there were 2,024,387 calves slaughtered under Government supervision, and probably fully as many without Government inspection.

It is seen from the foregoing that practically $5,000,000$ cattle, nearly $8,000,000$ sheep, and over 10,000,000 hogs were slaughtered by butchers in 1907 without Federal inspection, to which may be added about $3,000,000$ calves. All these 26,000,000 animals were consumed by the people of the United States, and the responsibility of inspecting them has rested wholly upon the State and local authorities, since they are beyond the reach of the Federal inspectors.

\section{LOCAL SLAUGHTERHOUSES AND THEIR EVILS.}

The slaughterhouses where animals are killed for local consumption are usually isolated and scattered about the city or town, either situated on some back street, surrounded by stables and dwelling houses, or outside of the corporate limits, each butcher apparently trying to avoid observation. In many instances the houses are located on the banks of streams or creeks, and the drainage is toward such streams. Frequently the offal is thrown on the banks to decay or to be devoured by hogs or rats.

Such houses, in addition to being unsightly, malodorous, unclean, and insanitary in the extreme, are actually centers for spreading disease. Where hogs are slaughtered it is more than probable that a hog infected with trichinæ will be killed. The offal of such a hog when eaten by rats will infect them, and these rats, if later killed and eaten by hogs, will again communicate the disease. Rats act as direct transmitters of trichinosis to hogs, and this is not the only disease which may be spread by offal feeding to hogs. 
Old worn-out dairy cows are not infrequently killed at these houses, and from the large amount of tuberculosis found in this grade of cattle it follows that tuberculosis will be communicated to hogs feeding upon the offal.

The local slaughterhouse is also the center of infection for a number of animal parasites which are injurious to live stock, or in some cases even to man, and which are spread by dogs. It is well known that dogs come to such slaughterhouses for food, and when infected viscera are eaten by them they become infected, and through them infection

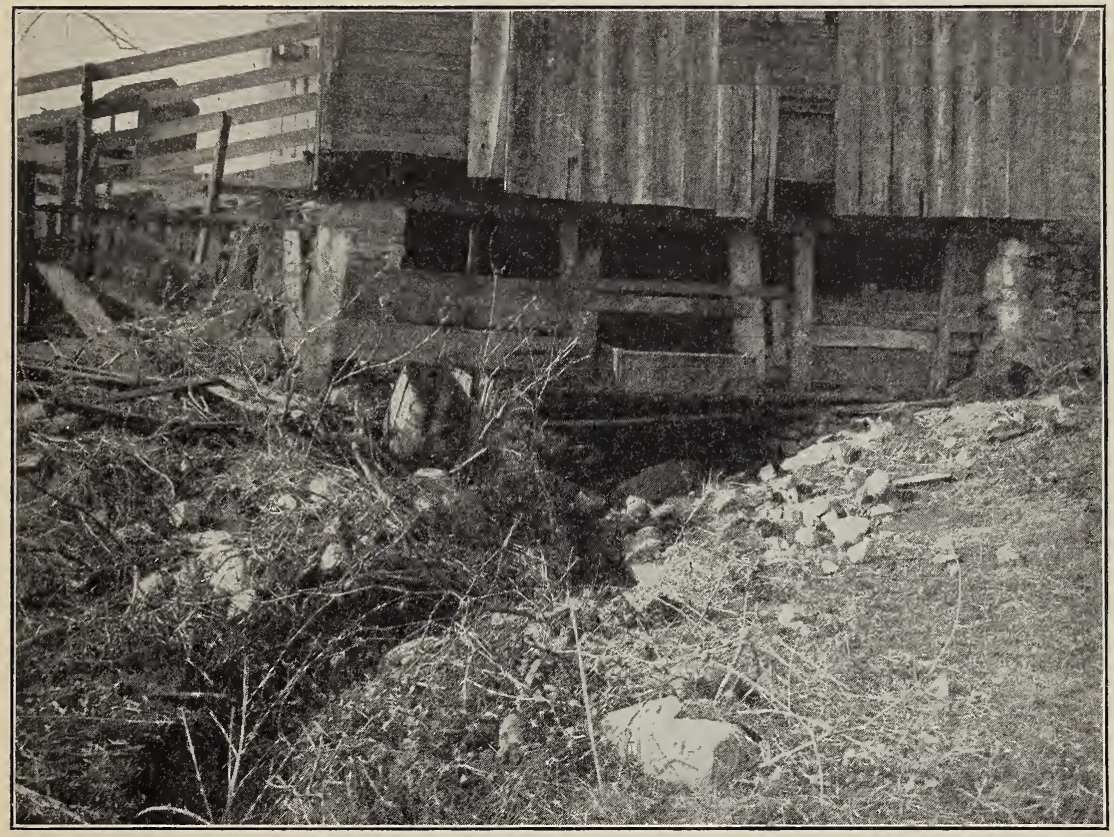

FIG. 1.-Insanitary conditions at small local slaughterhouse. Note the exposed drainage. Hogs are often fed on offal under such abattoirs, and rats and other animals have free access, thus favoring the spread of disease.

may be transmitted to other animals and to man. Several species of tapeworms are distributed in this manner.

Hog cholera is another disease which is spread from local slaughterhouses by improper disposal of the offal. This disease is communicated either by direct infection from hogs eating diseased viscera or by the infection being carried in rivers or creeks and spreading to farms lower down.

That the conditions which obtain at these local slaughterhouses need attention from authorities competent to deal with the situation is shown by a recent investigation made by the State board of health 
of Indiana of those slaughterhouses which do not have Federal inspection. The report stated that-

Of the 327 slaughterhouses inspected, only 23 , or about 7 per cent, were found to fulfill the sanitary standards. The standards called for in the Indiana purefood law, approved March 6, 1907, were accepted, and said standards are as follows :

"Insanitary conditions shall be deemed to exist wherever and whenever any one or more of the following conditions appear or are found, to wit: If the slaughterhouse is dilapidated and in a state of decay; if the floors or side walls are soaked with decaying blood or other animal matter; if efficient fly screens are not provided; if the drainage of the slaughterhouse or slaughterhouse yard is not efficient; if maggots or filthy pools or hog wallows exist in the slaughterhouse yard or under the slaughterhouse; if the water supply used in connection with the cleansing or preparing is not pure and unpolluted; if hogs are kept in

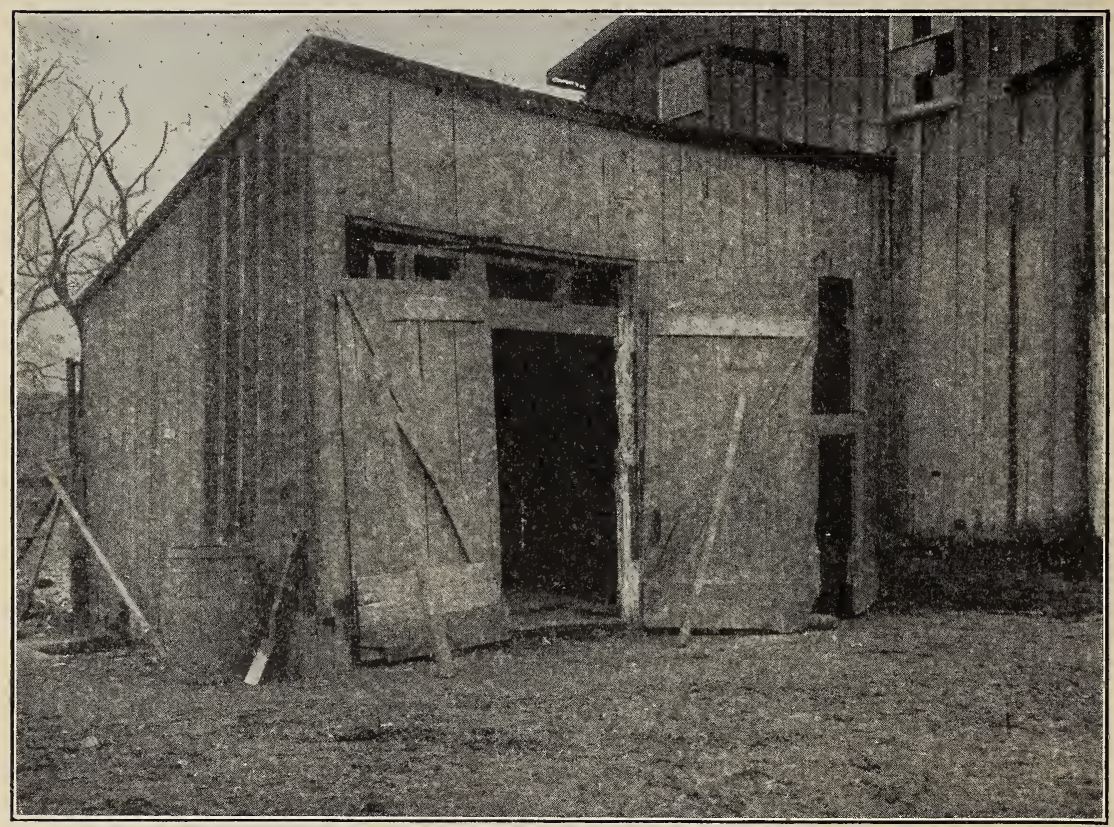

Fig. 2.-Place used as slaughterhouse and carriage house in suburbs of a city.

the slaughterhouse yard or fed therein on animal offal, or if the odors of putrefaction plainly exist therein; if carcasses or parts of carcasses are transported from place to place when not covered with clean white cloths, or if kept in unclean, bad-smelling refrigerators, or if kept in unclean or bad-smelling coldstorage rooms."

At nearly all slaughterhouses inspected, foul, nauseating odors filled the air for yards around. Swarms of flies filled the air and the buildings and covered the carcasses which were hung up to cool. Beneath the houses was to be found a thin mud or a mixture of blood and earth, churned by hogs, which are kept to feed upon offal. Maggots frequently existed in numbers so great as to cause a visible movement of the mud. Water for washing the meat was frequently drawn from dug wells, which receive seepage of the slaughterhouse yards, or the water was taken from the adjoining streams, to which the hogs had access. Dilapidated buildings were the usual thing, and always the most repulsive surroundings and odors existed. 
Slaughterhouses of fair sanitary condition were not found. They were all awfully and abominably bad or else met the standard completely.

A concrete example of conditions as they exist may be cited of a large eastern city. In this city there are 275 slaughterhouses which do not have Federal inspection. The approximate combined yearly kill at these plants is nearly 2,000,000 animals, as follows:

Cattle 38,000

Hogs 516,000

Sheep $1,230,000$

Calves 108,000

Total $1,892,000$

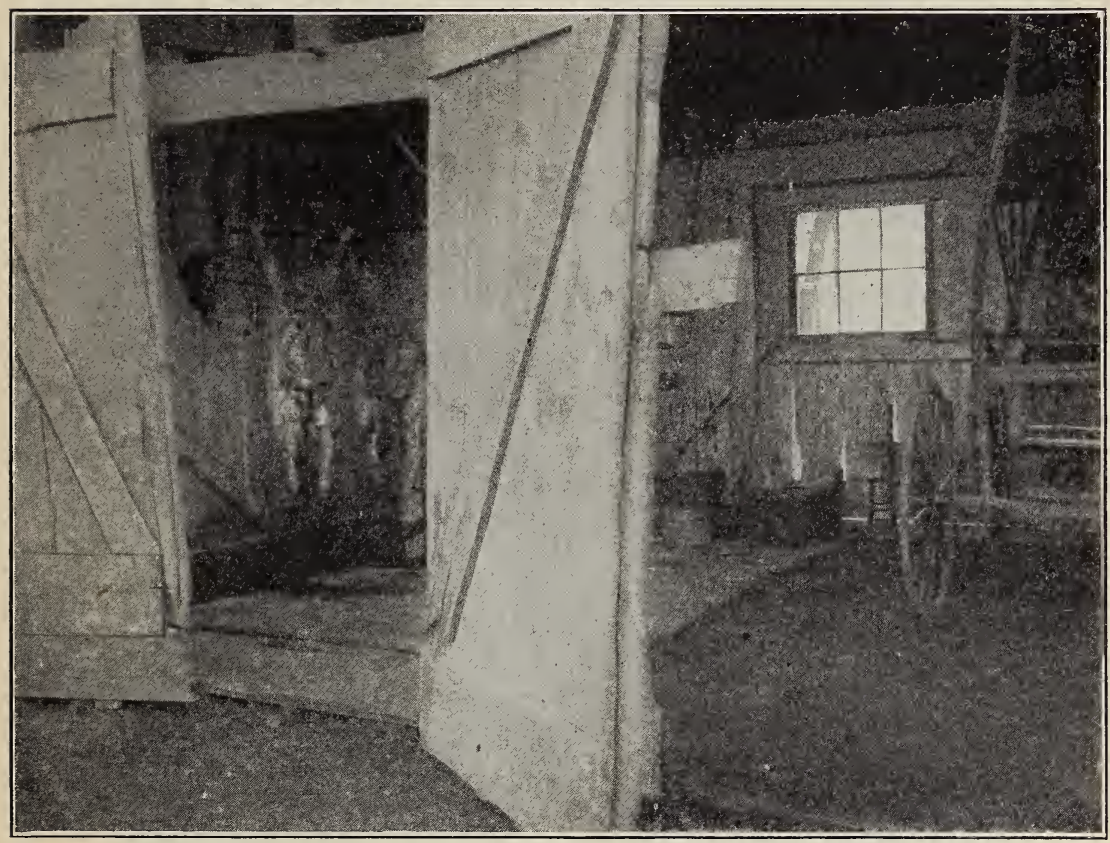

FIG. 3.-Interior of house shown in figure 2.

The meat-inspection force of this city consists of three men-one State inspector and two city inspectors-none of whom are reterinarians, but all of whom were formerly butchers. Their inspection necessarily must be hasty and superficial. It is, of course, a physical impossibility for these inspectors to make a post-mortem examination of all animals slaughtered. They merely make occasional visits to the killing beds, usually when cows are slaughtered.

One of the slaughterhouses of the larger sort in this city kills approximately 5,000 cattle, 150,000 sheep, and 50,000 calves a year, no hogs being slaughtered. This house has been described as follows:

The several departments of the establishment are each in a separate building. The killing department, for example, is in a large barnlike wooden structure. 
It has one floor and a basement. Cattle, sheep, and calves are killed in the basement and on the first floor. The basement is floored with cement, but the flooring in the room above is of wood, filthy and insanitary. When slaughtering is being done, heads and hides are piled in heaps on the fioor, and livers and tails are scattered about. Butchers frequently hold their knives in their mouths, wear grimy clothes, spit on the floor, and wash down carcasses with dirty water carried about in a bucket.

The ceilings, walls, and pillars are exceptionally dirty ; blood and fecal matter besmatter everything.

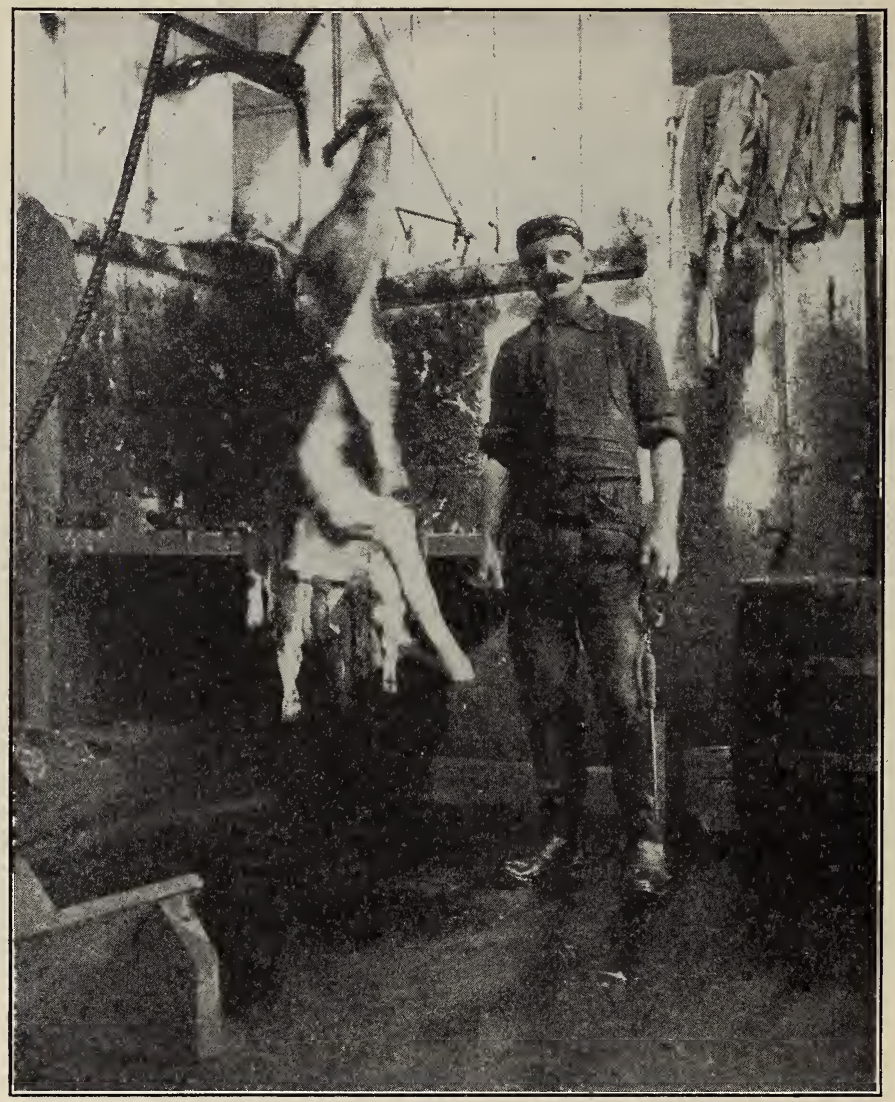

FIG. 4.-Calf-killing room in uninspected slaughterhouse. Observe filthy condition of walls and floor, and dirty clothes hanging on wall. This place handles 5 or 6 carloads of hogs and 10 to 15 cattle a week. The class of cattle killed is mostly worn-out dairy cows, many of which are tuberculous.

The trucks, trays, and other receptacles are filthy, as are the tables on which gut is remored. Chutes and cutting blocks are also dirty, and no effort is ever made to clean them. No toilet room is provided in the building.

The coolers or ice chests are in a revolting condition. The floors are wet and dirty, the walls damp. Livers are thrown on the floor; foul-smelling barrels are allowed to stand on the killing floor. The pens are in an inconceivably filthy condition. The top of the cooler is filled with cast-off shoes and clothes, 
hides and cans, and other refuse. Old clothing, reeking with filth, is allowed to hang on the walls of the building.

One of the butcher's was asked what they did with "sick" cattle. He laughed and answered, "What do they all do with them?" He told the inquirer that the butcher's who killed at this establishment did so because they were afraid to kill where there was inspection, because the Federal inspector's would condemn sick cattle. This simply proves the butchers are carrying out their threat to kill dairy cows where there is no inspection, and thereby put into the meat food trade of the country carcasses which no Federal inspector would ever have passed.

In another large eastern city there are only four slaughterhouses in the city proper which do not have Federal inspection. The total kill

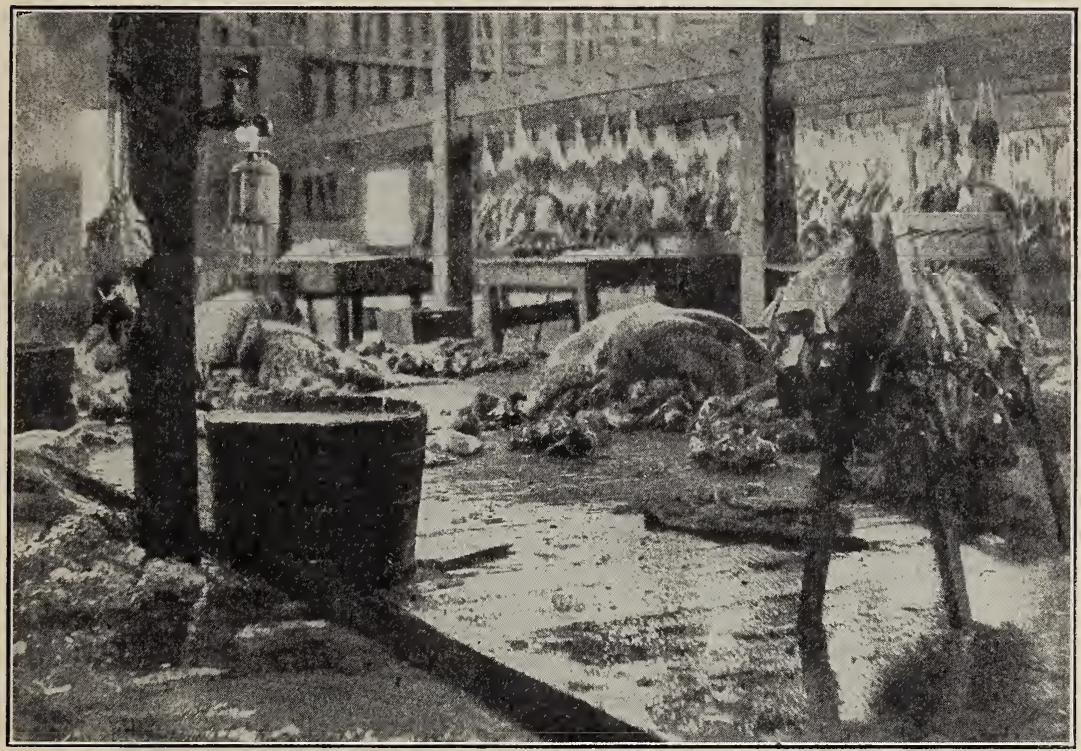

FIG. 5.--Interior of large slaughterhouse in an eastern city, showing insanitary conditions. Many animals which would be condemned under Federal inspection are slaughtered here and their meat is sold for local consumption. This place can not be reached by the Federal authorities, as its product is sold entirely within the State.

at these places is about 1,000 cattle and 2,500 hogs per month. The only inspection is furnished by one inspector of the board of health, and this inspector is not a veterinarian. Previous to his employment by the board of health he was a hotel porter. The sanitary condition of one of the establishments in this city is thus fairly described:

The place was built in 1872 and is falling to pieces, but little attenipt being made to repair it. This slaughtering house is composed of three rooms or compartments, each about 20 feet square, only partly partitioned off. One of the compartments is used for the killing and dressing of hogs, one for lard making, and the other as a storeroom for manufactured lard, utensils, boxes, barrels, etc. The gut cleaning is done in the lard room. Steam from the scalding tub, and the foul odor always more or less present in hog-killing rooms, come in 
direct contact with the lard in all stages of its manufacture and with the finished product. All floors are of wood and in a shocking condition. The place is supplied with running water, but the floors, walls, ceiling, tables, benches, etc., show but little eridence of its use. The loose material is swept from the floor, but the rest remains. Blood and manure are caked on the woodwork in places an inch thick. The blood and offal are conveyed by pipes and trapdoors to tank cars in basement, and from there taken to the rendering works. The cellar has a cement floor, but it is maintained in a filthy condition. There is no urinal, closet, or toilet connected with the place. The yard, pens, and runways are seldom cleaned, never during the winter months. There is manure in places a foot deep. Livers when first removed from the carcasses are thrown on the floor and later hung on dirty racks in the slaughtering room exposed to flies, filth, and the stench of the place.

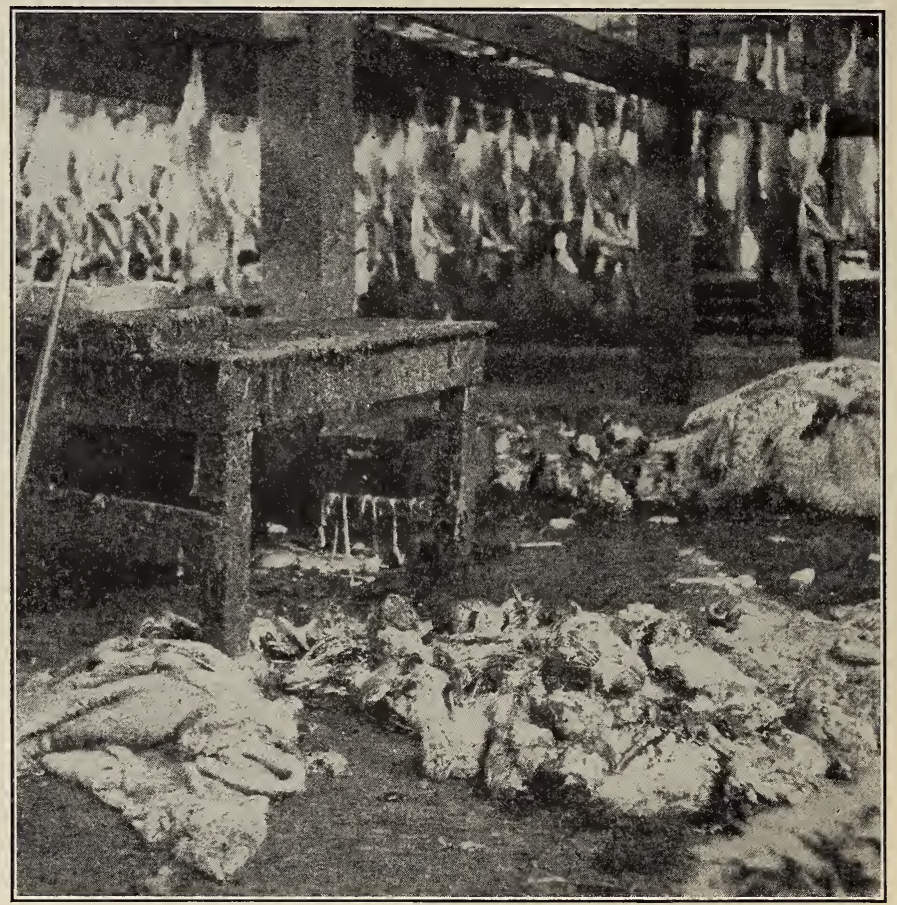

Fig. 6.-Another view of the same establishment shown in figure 5. Note filthy condition of table and floor; sheep pelts and heads strewn on floor.

By these few examples it can be readily appreciated that it is necessary to improve the efficiency of the inspection of meat and meat food products that are consumed entirely within a State.

\section{MUNICIPAL SLAUGHTERHOUSES.}

It is impossible to secure an effective system of local meat inspection without either a great increase in the number of competent meat inspectors employed or a concentration of the business of slaughtering. It is largely on account of the multiplicity of slaughterhouses 
that thorough systems of meat inspection have not been more generally established. In the small houses very frequently the slaughtering is done at night or very early in the morning, and it would necessitate the employment of a small army of meat inspectors to provide a sufficient number so that one should be present at each place.

The plan of concentration of slaughtering is supported by the experience of all the older civilized countries. It is recommended not only because it facilitates the inspection of meat but because of numerous other advantages. Since the local slaughterhouses are especially prolific sources for the spread of disease, the segregation of such places would materially reduce the number of centers of infection. It would eliminate all of the small, poorly built, badly managed slaughterhouses which are in many instances nuisances in their respective neighborhoods. It would give the small butchers the advantage enjoyed by wholesalers and the large packers, as they could use the machinery installed and the increased facilities supplied in the way of an abundance of hot and cold water for cleansing purposes, all of which are greatly superior in a large plant. The refrigeration also is much better in such a plant and would result in increased wholesomeness of meat to the consumers. The character of the local meat supply would gain in reputation, and local meats could enter into competition with those supplied by the large packers. Unless there is a competition of this kind the tendency of the trade at present is that the large packers will control the supply.

Instead of increasing the cost, the tendency of centralization is to reduce it. A large establishment conducted by cooperation among the butchers would naturally entail less expense than a number of small ones. Moreover, such a system is a great safeguard to the consumer of meats, while it subjects the butchers to no hardships whatever, but makes it more convenient' and cheaper for them to conduct their trade. In Europe such union or central abattoirs are owned by the municipalities, and undoubtedly this is the best system, since all butchers are assured of equal rights and privileges. Germany has more than 600 slaughterhouses belonging to municipalities.

If cities and towns of the United States are not prepared to adopt the plan of municipal abattoirs they can at least require a segregation of slaughtering and require animals to receive a careful postmortem inspection at the time of slaughter.

INCREASED VALUE OF BY-PRODUCTS.

One immense advantage to be derived from the consolidation of slaughterhouses would be the increased value received from the byproducts, which are practically lost by the small slaughterers.

That the value of such by-products is an important item is apparent from the statement of Mr. J. Ogden Armour, made to the 
Bureau of Corporations in the recent investigation of the beef industry. He spoke as follows:

The ability of wholesale butchers in the small towns to compete with the large packers in the sale of beef depends entirely upon conditions. At times such butchers can buy cattle so cheap that the large packers are almost excluded from doing business in their towns. When such a butcher has to buy his cattle in the same market that the large packers do, we are able, through our economies in manufacture and through making articles of value out of what would go to waste in his establishment, to sell to the retailers at a lower price than the local wholesale butcher can do.

From this statement and from other statements of a similar kind made in the investigation referred to, it is evident that the value of the by-products is an important source of profit; in fact, it has been stated that the packing business of to-day would be carried on at a loss but for the utilization of the by-products. Whether this be true or not, it must be conceded that the saving of these products and converting them into articles of commercial value is a powerful argument for the centralization of small slaughterhouses. It is by this plan of concentration that the modern packing business has grown to its present magnitude, and by following the same plan it is possible for the small butcher to reap substantial rewards.

We must bear in mind that when animals are slaughtered not all of the product is edible meat. Fat cattle, for instance, dress only about 60 per cent of the live weight, sheep 50 per cent, and hogs 80 per cent. The remainder need not be destroyed and become a total loss if there are proper facilities for handling it. This is done in modern abattoirs, but can not be accomplished where there is not suitable equipment. From packing-house statistics it appears, in the case of cattle, that the value of the hide and offal would probably increase the total percentage to 75 . In other words, the 40 per cent of offal is equivalent in value to about 15 per cent of meat.

The most valuable product, next to the beef, is the hide, which of course is usually saved by country butchers. But in large abattoirs where many cattle are killed the removal of the hide is so skillfully done that its value is much greater. Tanners pay three-fourths to 1 cent a pound more for such hides than they do for country hides, which are often cut or damaged in stripping.

The next important item is the tallow, which, when properly treated, becomes valiuble in the form of oleo oil and stearin. The feet, from which neat's-foot oil is extracted, the bones of the skull, the horns, and even the sinews, may be utilized. When machinery is available for proper preparation, the casings, which are entirely lost in small slaughterhouses, yield a good return, thus saving the expense of importing from foreign countries, which is now done to a large extent. 
Other by-products, such as tongues, livers, sweetbreads, beef hearts, tripe, and blood albumen, with proper attention and refrigeration, can be available for food, where formerly they were thrown away as useless and not worth the trouble required to keep them.

The tankage is still another product which is of value. The liquid that is pressed out of the tankage is saved, and, after boiling and treating with chemicals, is known as "concentrated tankage" and is sold on an ammonia basis.

An accurate idea of the value of slaughterhouse by-products can be gained by referring to an example cited in F. W. Wilder's book, The Modern Packing House. This book is an acknowledged authority on the packing business, and the data presented refer to the yield of a bunch of 34 cattle, obtained in actual operation at the prevailing market prices (1905).

Yield of 34 cattle.-Average live weight, 1,259 pounds; average dressed weight, 750 pounds; average weight of hide, 89 pounds. Excluding the dressed meat and the hides, the remainder (offal) realized as follows:

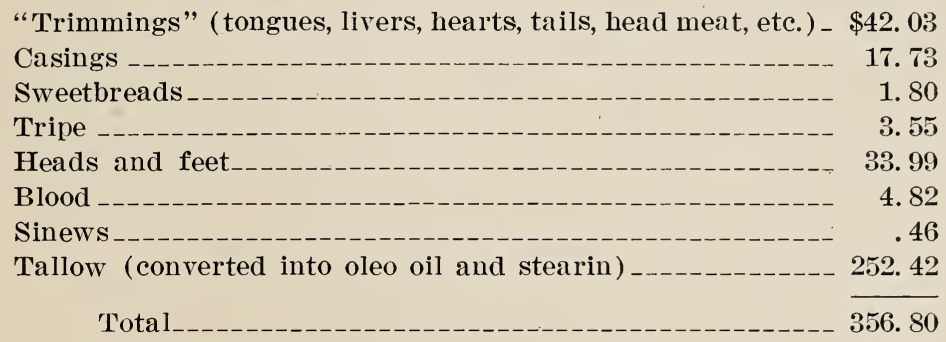

In addition to the above there were 2,665 pounds of "tankage," being 78.38 pounds a head. This tankage consists of the bony portions of the heads, and all the other refuse of the slaughtering operations. This material is rendered in the tank, and after extracting the fat the residue is converted into more or less valuable by-products, as ammonia, etc. This matter of tankage, in particular, illustrates the close business methods that are being applied in the modern abattoir.

However, taking the total value of the offal, including tallow, as given above, and dividing by the number of cattle experimented with (34), the value of offal per head is seen to be $\$ 10.49$. If to this is added the tankage at $\$ 16$ a ton, the total is increased to $\$ 11.05$. Assuming that the animals cost an average of $\$ 80$ a head alive, the offal then amounted to fully 14 per cent of the live value, which gives a good indication of how much may be lost through wasteful methods. Similar economy is exercised in the slaughter of sheep and hogs; it is therefore unnecessary to go into details in regard to these classes of 
animals. What has been said shows without doubt that the loss of the whole or any considerable part of the by-products would make a very appreciable difference in a year's operation at any good-sized abattoir.

It would seem, if for no other reason than the saving of these byproducts, that concentration in slaughtering and competent inspection should be advocated and upheld from a commercial point of view.

\section{PUBLIC EFFORT NECESSARY FOR REFORM.}

Since the Federal law will not permit meat slaughtered under the insanitary conditions herein mentioned to enter into interstate and foreign trade, nothing remains but for it to be consumed within the State; it is therefore necessary for public opinion and effort to bring about a more cleanly and healthful condition in this direction. Let organizations having similar objects in view as this bring before the people the revolting conditions under which some of our meat is supplied and public sentiment will soon force those in authority to take measures to better these conditions.

This question of an adequate State inspection of meat was emphasized by Miss Alice Lakey, chairman of the food committee of the National Consumers' League, in an address delivered at the Jamestown Exposition July 19, 1907, in connection with the eleventh annual convention of the Association of State and National Food and Dairy Departments. Miss Lakey said, in part:

Will not this body of State and National officials use its influence to help in prevention by securing State inspection of cattle, slaughterhouses, and meat? Why are so many consumers acceding to the demands of the meat trust by paying increased prices for meat? Because such meat bears the stamp of the Federal inspector and the consumer has been educated by the public press to believe that such meat is safe. Many consumers refuse all meat not so labeled. Can not the States give consumers a label on State meat that shall be equally reassuring?

It is only fair to say, in conclusion, that a packer who submits to Federal inspection and destroys all animals that are unfit for food purposes incurs a heavy expense not known to the slaughterer who has no inspection of any kind and who sells diseased meat at the same price that he receives for healthy meat. Consequently the packer or slaughterer whose product is subjected to a rigorous inspection should receive, in all fairness, a higher price for his product than the packer or slaughterer who operates without inspection. 

